failure to give warning of the fire earlier. However, the degree of her culpability is much reduced by the revelation that she had never had training in fire procedure in the whole of her 22 years' service. Nor do the resident fireman, the group chief engineer responsible for fire prevention and safety throughout the Shrewsbury Group of Hospitals, the hospital secretary, the medical superintendent, or the hospital management committee avoid censure in greater or less degree.

What are the principal lessons to be learned from this disaster? The first and by far the most important is that fire-fighting is a job for professionals and the sooner they are summoned the better. The second follows therefore from the first-namely, that communication between any part of a hospital, its fire-control centre, and the local fire service should be as simple and foolproof as possible. Ideally, the raising of the alarm should register directly in the fire service headquarters. Thirdly, a chain of command and responsibility for training all grades of staff in fire procedure should be established. Lastly, all staff must be instructed in firefighting and evacuation of patients by lectures, demonstrations, and "dummy runs," preferably given or supervised by officers of the fire service. But here's the rub: Shelton Hospital was admittedly understaffed on the night of the fire, though the inquiry does not consider the understaffing to have been a significant factor. Nevertheless, it must surely be conceded that the one night nurse who was in sole charge of a ward housing 42 patients, some of whom are described as especially disturbed, continuously from 8 p.m. to 8 a.m., bore a very heavy responsibility.

But the night staffing situation at Shelton is by no means unique. There may be mental hospitals where staff are more plentiful, but there are certainly others where they are even fewer. And of those that can be pressed into service some are available only on a part-time basis. To train all staff, permanent and part-time alike, in fire procedures to any standard of proficiency is undoubtedly an enormous task. Reading this report, no one can afford to be smug. And anyone concerned with the administration of mental hospitals could be forgiven for mopping his anxious brow and muttering, "But for the grace of God ..."

\section{Facts about Venereal Disease}

It is generally agreed that the public ought to be well informed about the venereal diseases in the hope that accurate knowledge will help to prevent the spread of them. In these days the people who control the media of information are willing enough to devise programmes and write articles about the subject. Indeed, one of the additional burdens carried by the already overpressed venereologist is that of visits and questions by newspaper reporters and television producers. This might be an excellent way of putting facts before the public, but unhappily writers and producers are too often drawn irresistibly towards the more sensational aspects of the problem. There is no evidence that the kind of publicity they provide exerts any appreciable effect on promiscuity or that it brings more infected patients to the clinics. Those who respond to this stimulus are more often than not stirred by anxieties, newborn or revived from the past.

An excellent but neglected source of accurate information and sober analysis is provided year by year in the annual report of the Chief Medical Officer of the Ministry of Health. The latest report, for $1967,{ }^{1}$ indicates that the numbers of cases of some of the venereal diseases are increasing. Nevertheless, it is satisfactory to note that infectious syphilis, an intractable problem in many countries, has remained at a low level in England and Wales and has in fact diminished in the past two years. Thus, 1,321 cases of primary and secondary syphilis were reported from the venereal disease clinics in 1967, of which 1,075 were in men and 246 in women, giving a reduction of $3.8 \%$ from the total for 1966 and a male: female ratio of $4.4: 1$. In the population as a whole the incidence of infectious syphilis in males was 4.56 per 100,000 and in females 0.99 . These figures are certainly lower than those reported in the U.S.A., where the rate per 100,000 population was 10.8 in $1967,{ }^{2}$ though exact comparisons are not possible. The C.M.O.'s report comments that the numbers for England and Wales are small by any standards, and it is difficult to draw from them reliable conclusions other than the obvious one that control measures have proved successful within limits. The reduction in primary and secondary cases occurred only in men, and it was thought that this fact may reflect the increasing diligence with which sources of infection are being traced and brought under treatment.

On the other hand the figures for gonorrhoea are disquieting. In 1967 there were 41,829 cases, an increase of $11.6 \%$ over 1966 and the highest number reported from the clinics since 1946, the postwar peak year. Cases in adult men rose from 27,913 in 1966 to 30,630 in 1967 and those in adult women from 9,465 to 11,081 . The male: female ratio was 2.8: 1 in 1967 and 2.9 in 1966 . These figures suggest that in spite of difficulties contact tracing has been pursued diligently, so that many infected women who through lack of symptoms might remain sources of infection are being brought under treatment. The contribution made by immigrants to cases of gonorrhoea has been studied by the Co-operative Clinical Group of the Medical Society for the Study of Venereal Diseases, and some of the figures are included in the report. Returns from 169 clinics in England and Wales related to 38,066 cases-that is, $91 \%$ of the national total. Of 27,979 men suffering from gonorrhoea, $56.4 \%$ were born in the United Kingdom, as compared with $54.6 \%$ in the similar study for 1966 . Of 10,087 women with the infection $82.1 \%$ were born here, as compared with $82.4 \%$ in 1966. Thus, although immigrants still make a considerable contribution to this problem, there is no evidence that it is an increasing one.

Cases of non-gonococcal urethritis in men continued to increase, amounting to 32,318 as compared with 30,462 in 1966. For the past three years these cases in men have outnumbered those of gonorrhoea.

In his comments the Chief Medical Officer points out that at least 200 fresh infections occurred on any average day" an epidemic by any standards." Spread of disease is due to promiscuity and it is high time that the magnitude of this problem was more widely known. His report concludes that syphilis could be controlled even in a society in which extramarital intercourse is regarded by many as a normal and permissible activity. But gonorrhoea is a more infectious disease with a short incubation period, and often gives rise to no symptoms in women. It is a much more difficult disease to control. Without a change in public attitude there seems

\footnotetext{
Annual Report of the Chief Medical Officer of the Ministry of Health for the year 1967, pp. 65 and 279, 1968. H.M.S.O.

2 Today's V.D. Control Problem. A Joint Statement. The American Social Heaith Association, p. 48, 1968 . New York.
} 
small hope of diminishing its incidence unless there is some major advance in prophylaxis or treatment, neither of which seems in prospect at present. Further advances in the control of non-gonococcal genital infection await the discovery of a causative organism or organisms, but this is proving a difficult task. It seems likely that modern methods of contraception, which provide no element of mechanical protection, favour the spread of gonorrhoea and non-gonococcal urethritis.

\section{Complications of Cardiac Massage}

Since W. B. Kouwenhoven and his colleagues $^{1}$ evolved a simple method of external cardiac massage it has been increasingly used as emergency treatment in cases of sudden cardiac arrest. In a series they reported almost half (48\%) of the patients thus treated were resuscitated and $25 \%$ survived. ${ }^{2}$

Of the complications that may follow external cardiac massage the commonest is fracture of the ribs, seen in about a third of cases, the proportions varying from $28 \%$ to $50 \%$ in different series. ${ }^{3}$ Less common but more serious is injury to abdominal viscera, notably the liver ${ }^{4}$ and occasionally to the spleen and adrenal glands. ${ }^{5}$ G. D. Lundberg and colleagues ${ }^{6}$ noted gastro-oesophageal tears and intestinal haemorrhage in $10 \%$ of 348 necropsies.

Now F. Paaske and his colleagues ${ }^{7}$ from the University Institute of Forensic Medicine in Copenhagen have made a four-year survey of 3,306 necropsy examinations which included 323 patients who had received external cardiac massage. Of the latter some $17 \%$ had to be excluded from further consideration owing to previous injury to the chest wall, leaving a total of 180 males and 88 females. In most instances massage was performed by a physician and in only $8 \%$ by an unqualified person, but there appeared to be no difference between the groups in the complication rate. Rib fractures were found at necropsy in $44 \%$, increasing in frequency with age and bilateral in half the cases. There were sternal fractures in $22 \%$, only in patients over 20 years of age, and minor cardiac lesions in the form of surface haemorrhages were seen in $16 \%$. More serious complications were injury to the liver, in $2 \%$, injuries to the spleen and adrenal gland, and the inferior vena cava, each in one case. Bone marrow emboli were noted only once. Other workers have found marrow emboli in some $10-20 \%$ of cases examined. $^{8}$ 9 C. T. Jackson ${ }^{10}$ found pulmonary fat embolism in $81 \%$ of cases, with 4 cases of cerebral fat embolism, but there was no correlation between its occurrence and fracture

\footnotetext{
Kouwenhoven, W. B., Jude, J. R., and Knickerbocker, G. G., f. Amer. med. Ass., 1960, 173, 1064 .

Jude, J. R., Kouwenhoven, W. B., and Knickerbocker, G. G., Monogr.

Jude, J. R., Kouwent. $1964,1,59$.
surg. Sci.,
Bynum, W. R., Connell, R. M., and Hawk, W. A., Cleveland Clin. Quart., 1963, 30, 147.

Morgan, R. R., New Engl. f. Med., 1961, 265, 82

5 Bynum, W. R., Connell, R. M., and Hawk, W. A., Cleveland clin. Quart., 1963, 30, 147.

6 Lundberg, G. D., Mattei, I. R., Davis, C. J., and Nelson, D. E., 7. Amer. med. Ass., 1967, 202, 195.

Paaske, F., Hansen, J. P. H., Koudahl, G., Olsen, J., Dan. med. Bull.,

1968, 15, 225.
Silberberg, B., and Rachmaninoff, N., Surg. Gynec. Obstet., 1964, Silberberg,

9 Baringer, J. R., Salzman, E. W., Jones, W. A., and Friedlich, A. L., New Engl. f. Med., 1961, 265, 62.

to Jackson, C. T., and Greendyke, R. M., Surg. Gynec. Obstet., 1965, 120,25 .

\$1 Stephenson, H. E., Reid, L. C., and Hinton, J. W., Arch. Surg., 1954, 69, 37.
}

of ribs, so it may be accounted for by vigorous chest compression. Paaske and his colleagues' conclusions were that $1 \%$ of cases showed serious complications which would have resulted in death.

The dangers of closed cardiac massage should be borne in mind, as they are inherent in the method. The pathologist doing the necropsy can help by drawing them to the attention of his colleagues, and he should also distinguish rib injuries from possible pre-existing trauma, otherwise a serious medicolegal error could occur. Experience in the U.S.A. suggests it is unlikely that a malpraxis suit would be successful against a physician employing this method of resuscitation. ${ }^{11}$

\section{Safer Smallpox Vaccines}

In countries where smallpox is endemic the risks associated with vaccination are insignificant compared to the high morbidity and mortality of the disease. But in countries where the disease has been eradicated the case for routine vaccination has been questioned. In a recent report by C. H. Kempe ${ }^{1}$ we are reminded that in the United States the last death from smallpox to follow import of the disease occurred in 1948, but since that time there have been between 200 and 300 deaths from vaccination. Such data support those who advocate stopping routine vaccination and vaccinating only persons in an area surrounding an imported case. The weakness of this argument is that in these days of rapid travel much movement and contact may have taken place before the case is diagnosed. Moreover, if no improvements in the vaccines are made, the people vaccinated during an emergency will be exposed to the risk of complications. Furthermore, if this policy was pursued for several years, some primary vaccinations would be given to people in later life, when the risk of complication-especially of encephalitis -is greater than among young children. ${ }^{2}$ Clearly a more satisfactory approach would be to develop a safer vaccine. Such a vaccine is even more urgently required for eczematous children, who even if not vaccinated are at risk from accidental contamination with vaccinia from a vaccinated sibling or classmate. Indeed, several studies have shown that eczema vaccinatum is a much more serious disease in accidentally contaminated infants than in elective primary vaccination of those liable to eczema, in whom virus infection will only occasionally become generalized.

The present methods of manufacture of smallpox vaccine have changed little throughout the century. Lymph harvested from the inoculated skin of animals is made "safe" by killing pathogenic bacteria with phenol, but it is far from being bacteriologically sterile. Two major improvements must be made. The production methods must come into line with those applied to the more recent virus vaccines, and a more attenuated, though still protective, strain should be used. The report from Kempe ${ }^{1}$ is particularly pertinent here. Over the last 20 years he has been studying the reactogenicity and efficacy of a vaccinia virus which has been passaged 10 times in rabbit testicles, 49 times in chick embryonic tissue, and 19 times in chicken-egg chorioallantoic membranes. The virus harvested at the 78 th passage

Kempe, C. H., Yale 7. Biol. Med., 1968, 41, 1.

2 Conybeare, E.'T., Mth. Bull. Minist. Hlth Lab. Serv., 1964, 23, 150

3 Kempe, C. H., Pediatrics, in press.

Kempe, C. H., unpublished data. 